\title{
PERISTIWA PENAHANAN DAN PENDAKWAAN DATO' SERI ANWAR IBRAHIM DALAM HUBUNGAN MALAYSIA-AMERIKA SYARIKAT, 1998-2004
}

\author{
Azslan Selamat \\ Shakila Parween Yacob
}

\begin{abstract}
Abstrak
Peristiwa penahanan dan pendakwaan Dato' Seri Anwar Ibrahim memberi kesan terhadap hubungan Malaysia-Amerika Syarikat (AS) bermula dari tahun 1998 sehingga tahun 2004. Oleh itu, makalah ini akan menumpukan perbincangan terhadap sikap kedua-dua buah negara dalam berhadapan dengan kes Dato' Seri Anwar Ibrahim yang didakwa terlibat dengan rasuah, salah guna kuasa dan salahlaku seksual. Kaedah analisis sejarah digunakan menerusi kajian ini dalam menjelaskan pengaruh peristiwa berkenaan terhadap hubungan Malaysia-AS. Selain data primer dan sekunder, kaedah temu bual turut digunakan dalam memantapkan hujah yang diutarakan. Menerusi kajian ini telah dikenal pasti bahawa wujud pengaruh yang signifikan apabila kes ini dibawa ke Kongres AS dalam membincangkan tindakan lanjut yang boleh dikenakan ke atas Malaysia. AS termasuklah pihak media Barat lebih memihak kepada Dato' Seri Anwar Ibrahim. Campur tangan AS telah menimbulkan konflik apabila kedua-dua buah negara saling mengkritik dan menyalahkan antara satu dengan yang lain serta mengeluarkan kenyataan yang menaikkan kemarahan kedua-dua belah pihak. Peristiwa ini juga dilihat mempunyai pengaruh yang tersendiri apabila melibatkan konflik antara Malaysia dengan negara ASEAN yang lain termasuklah organisasi antarabangsa seperti UNESCO, Pertubuhan Bangsa-bangsa Bersatu (PBB). Walau bagaimanapun, hubungan kedua-dua buah negara kembali pulih apabila dakwaan ke atas Dato' Seri Anwar Ibrahim telah digugurkan pada tahun 2004 kerana kekurangan bukti mengenai salahlaku seksual. Peristiwa ini memberikan gambaran bahawa masalah dalaman Malaysia juga mampu menjejaskan hubungan bilateral Malaysia dengan negara lain khususnya AS. Makalah ini bukan sahaja mengisi kelompangan sorotan literatur terdahulu yang kurang menyentuh pengaruh peristiwa penahanan dan pendakwaan Dato' Seri Anwar Ibrahim dalam hubungan Malaysia-AS, malah diharap menyumbang dengan memperkayakan lagi koleksi literatur dalam sejarah hubungan Malaysia-AS di Malaysia.
\end{abstract}

\begin{abstract}
This paper discusses the influence of Dato' Seri Anwar Ibrahim's arrest and prosecution on Malaysia-US relations from 1994 to 2004. The focus of the discussion is on the attitudes of both countries in dealing with the case of Dato' Seri Anwar Ibrahim who is alleged to be involved in corruption, abuse of power and sexual misconduct. The historical analysis method is applied to explicate the influence of this event on Malaysia-US relations. Besides primary and secondary data, the interview method is also used to further enhance the author's argument of the US intervention in the case of Dato' Seri Anwar Ibrahim's arrest and prosecution. A significant influence was detected when the case was brought to the US Congress for further discussion on the possible action that could be imposed on Malaysia. The US, including the Western media, was more inclined towards Dato' Seri Anwar Ibrahim. The US intervention had sparked off conflict when both countries were criticizing and
\end{abstract}


blaming each other as well as issuing provocative statements. This event is also deemed having its influence on the conflicts between Malaysia and other ASEAN countries including the international organization, United Nations (UN). Nevertheless, the event has a more significant influence on Malaysia-US relations. However, the two countries' relations recovered when the allegations of sexual misconduct against Dato' Seri Anwar Ibrahim were dropped in 2004 due to lack of evidences. This episode illustrates that the internal affairs of Malaysia could influence its bilateral ties with other countries, especially the US. The current paper does not just fill the void in the previous publication and literature, which barely mention about the influence of the arrest and prosecution of Dato' Seri Anwar Ibrahim towards Malaysia-US relations, but it is also enriches the collection of literature of Malaysia-US relations in Malaysia.

\section{Pengenalan}

AS merupakan salah sebuah kuasa besar dunia yang sering berusaha menyelesaikan masalah di persekitaran antarabangsa. Seiring dengan usaha tersebut, AS turut menjalinkan hubungan dengan banyak negara khususnya dalam mempromosikan dasar luarnya berkaitan demokrasi dan hak asasi manusia. Perkara ini juga berlaku ke atas Malaysia khususnya dalam peristiwa penahanan dan pendakwaan Dato' Seri Anwar Ibrahim. Tindakan AS ini turut menimbulkan konflik dengan Malaysia kerana kurang senang dengan tindakan AS yang didakwa campur tangan dalam urusan pentadbiran Malaysia semasa mengendalikan kes Dato' Seri Anwar Ibrahim. Makalah ini membincangkan mengenai pengaruh peristiwa penahanan dan pendakwaan Dato' Seri Anwar Ibrahim ke atas hubungan Malaysia-AS serta respon kedua-dua buah negara ke atas perjalanan kes pendakwaan Dato' Seri Anwar Ibrahim. Isu ini turut meninggalkan kesan yang mendalam terhadap hubungan kedua-dua buah negara. Hujah ini berpendapat, campur tangan AS dalam peristiwa ini sedikit sebanyak menjejaskan hubungan Malaysia-AS. Persoalan yang cuba dijawab ialah: Bagaimanakah isu penahanan dan pendakwaan Dato' Seri Anwar Ibrahim mempengaruhi hubungan Malaysia-AS? Apakah respon yang ditunjukkan oleh Malaysia apabila AS ikut campur tangan dalam kes ini? Bagaimanakah kedua-dua buah negara mengurangkan ketegangan yang wujud menerusi peristiwa ini?

Kajian literatur terdahulu kurang ataupun hanya menyentuh mengenai peristiwa ini secara ringkas sahaja. Seperti Pamela Sodhy dalam monograf bertajuk Malaysia-US Relations 2000-2011 $1^{1}$ hanya membincangkan sedikit mengenai peristiwa penahanan dan pendakwaan Dato' Seri Anwar Ibrahim. Begitu juga dengan penulisan lain yang lebih tertumpu ke atas perjalanan kes pendakwaan Dato' Seri Anwar Ibrahim berbanding menumpukan perbincangan mengenai pengaruh peristiwa ini ke atas hubungan Malaysia-AS. ${ }^{2}$ Selain itu, terdapat beberapa kajian dan penulisan membincangkan mengenai hubungan Malaysia-AS tetapi, tidak menumpukan ke atas peristiwa penting ini. ${ }^{3}$ Justeru, makalah ini akan mengisi kelompangan sorotan literatur terdahulu dengan memberi tumpuan kepada pengaruh peristiwa ini yang dibincangkan secara mendalam dalam hubungan Malaysia-AS dengan menggunakan analisis sejarah ke atas data primer dan sekunder yang diperolehi daripada rekod Parlimen Malaysia, rekod Kongres AS, keratan akhbar, artikel dalam jurnal, buku dan temu bual. Perbincangan ini juga penting diketengahkan dalam konteks hubungan Malaysia-AS kerana menjelaskan mengenai hubungan negara kecil dan kuasa besar yang mempunyai pasang surutnya. Isu ini penting kerana menunjukkan perjalanan 
politik Dato' Seri Anwar Ibrahim khususnya yang berkaitan dengan hubungan Malaysia-AS. Pada masa yang sama, Dato' Seri Anwar Ibrahim sekarang telah kembali ke arena politik Malaysia dan kajian kes ini menjadi relevan dalam konteks perjalanan politik kedua-dua buah negara hari ini.

\section{Latar Belakang Penahanan dan Pendakwaan Dato' Seri Anwar Ibrahim}

Peristiwa pemecatan Dato' Seri Anwar Ibrahim telah dibahaskan dan dikaitkan dengan pelbagai faktor khususnya faktor kredibiliti, ekonomi dan politik. Faktor kredibiliti pemecatan Dato' Seri Anwar Ibrahim pada 2 September 1998 dari jawatan Timbalan Perdana Menteri Malaysia pernah dinyatakan oleh Tun Dr Mahathir Mohamad dalam buku bertajuk Doktor Umum. Menurut Tun Dr Mahathir, pemecatan Dato' Seri Anwar Ibrahim disebabkan perwatakan Anwar yang meragukan dan tidak layak menggantikannya sebagai Perdana Menteri Malaysia yang seterusnya.

Saya sama sekali tidak boleh membenarkan seorang yang berwatak meragukan menjadi pengganti saya sebagai Perdana Menteri Malaysia. Malah, saya tidak boleh membiarkan langsung beliau berada di dalam kerajaan. Tindakan dan kepura-puraan beliau berlagak sebagai seorang yang warak tidak boleh diterima. Saya juga mendapati cara beliau memerangkap dan kemudian memaksa mangsa menutup mulut adalah sangat menjijikkan. ${ }^{4}$

Tambahan pula, pada ketika itu, Datuk Seri Dr Mahathir tidak mahu disalahkan kerana menyembuyikan rahsia sekiranya perkara tersebut terbongkar. Sekiranya Dato' Seri Anwar Ibrahim menjadi Perdana Menteri, kedudukan Dato' Seri Anwar dianggap akan sentiasa dalam keadaan yang lemah kerana perbuatan beliau akan digunakan untuk memeras ugut kedudukannya. ${ }^{5}$ Menurut Tan Sri Syed Hamid Albar, ${ }^{6}$ Datuk Seri Dr Mahathir bekerja keras melatih Dato' Seri Anwar untuk menggantikan beliau sebagai Perdana Menteri Malaysia kerana Anwar dilihat mempunyai kredibiliti untuk menjawat jawatan perdana menteri. Walau bagaimanapun, apabila muncul isu yang mengancam masalah-masalah peribadi Dato'

Seri Anwar, Datuk Seri Dr Mahathir terpaksa menyingkirkan Dato' Seri Anwar kerana tidak mahu kelemahan Anwar itu digunakan untuk menjatuhkan beliau. Menurut Tan Sri Syed Hamid Albar:

Dalam politik, menjadi satu kebiasaan orang akan menggunakan segala masalah yang ada. Kelemahan kita akan diambil untuk menjatuhkan. Sedangkan negara yang tidak bermoral pun, jika dalam politik, isu moral pun jadi penting dalam soal kepimpinan. ${ }^{7}$

Walau bagaimanapun, faktor kredibiliti ini bertentangan dengan laporan akhbar Barat khususnya akhbar AS yang menyatakan pemecatan Dato' Seri Anwar Ibrahim sebagai Timbalan Perdana Menteri dan Menteri Kewangan disebabkan oleh perbezaan pendapat mengenai dasar ekonomi dengan Perdana Menteri Datuk Seri Dr Mahathir Mohamad. ${ }^{8}$ Perbezaan pendapat mengenai dasar ekonomi tersebut merupakan antara usaha untuk memulihkan ekonomi Malaysia yang dilanda krisis ekonomi Asia bermula pada bulan Julai 1997. Pemecatan Dato' Seri Anwar disahkan selepas pengumuman pelan kawalan pertukaran mata wang untuk menyelamatkan 
Ringgit Malaysia yang mengalami penurunan nilai. ${ }^{9}$ Namun, pernyataan tersebut tidak selari dengan pendirian Datuk Seri Dr Mahathir bahawa tuduhan tersebut tidak benar kerana perbezaan pendapat antara beliau dan Dato' Seri Anwar Ibrahim boleh menjadi bahan perbahasan dan perbincangan yang sihat di dalam Kabinet. ${ }^{10}$

Sebagai usaha untuk memulihkan ekonomi Malaysia, Dato' Seri Anwar dan bank pusat telah memilih untuk mengenakan kadar faedah yang tinggi dan langkahlangkah penjimatan untuk mengawal mata wang Malaysia. Manakala, Datuk Seri Dr Mahathir dan Pengarah Eksekutif Majlis Tindakan Ekonomi Negara, Abdul Daim Zainuddin, menolak dasar tersebut dan menggantikannya dengan dasar perbelanjaan kerajaan yang lebih tinggi dengan kadar faedah yang rendah. ${ }^{11}$ Sikap AS yang tidak menyokong pendekatan Datuk Seri Dr Mahathir jelas apabila Setiausaha Bendahara AS, Robert E. Rubin menyatakan, "Misguided exchange and capital controls are not the answer for dealing with the effects of this crisis." 12

Menurut Zainuddin Maidin dalam artikel bertajuk "Anak UMNO Pantang Derhaka" yang diterbitkan oleh Utusan Malaysia, pada ketika itu dunia luar sedang menerima isyarat yang berbeza antara Datuk Seri Dr Mahathir dan Dato' Seri Anwar dalam usaha memulihkan ekonomi Malaysia. Negara Barat khususnya AS melihat pandangan Dato' Seri Anwar adalah lebih baik dan menganggap beliau sebagai reformer ekonomi yang terbaik bagi Malaysia. ${ }^{13}$ Selain itu, AS turut berhasrat menanam modal di Malaysia bagi membantu memulihkan ekonomi Malaysia. Walau bagaimanapun, Datuk Seri Dr Mahathir telah menolak cadangan tersebut kerana tidak mahu wujud campur tangan AS dalam usaha memulihkan ekonomi Malaysia. Tindakan Datuk Seri Dr Mahathir itu telah menyebabkan AS mengkritik Malaysia kerana enggan menerima cadangan tersebut. Perkara ini berbeza dengan pendapat AS, menurut duta AS di Malaysia, John R. Malott, campur tangan AS adalah perlu untuk memulihkan ekonomi Malaysia pada ketika itu. ${ }^{14}$

Pada bulan Julai 1998, ketika persidangan agung tahunan UMNO, Dato' Seri Anwar berada di barisan hadapan melancarkan kempen pembaharuan politik dalaman UMNO. Dato' Seri Anwar juga telah mengadakan perhimpunan untuk mendapatkan sokongan kempen yang dilancarkan oleh beliau. ${ }^{15}$ Semasa kempen tersebut berlangsung, Dato' Seri Anwar Ibrahim telah mendakwa Datuk Seri Dr Mahathir sebagai seorang yang paranoia dan enggan membuat pembaharuan dalam UMNO dengan segera. Menurut Dato' Seri Anwar, Datuk Seri Dr Mahathir merasa terancam kerana terdapat beberapa individu yang merancang untuk menggulingkan beliau sebagai presiden parti UMNO. ${ }^{16}$ Sebagai respon, Datuk Seri Dr Mahathir telah mematahkan kempen tersebut melalui kempen anti-Nepotisme di bahagian peringkat tertinggi kerajaan. Akibatnya, Dato' Seri Anwar Ibrahim telah diusir keluar semasa persidangan UMNO. Pada masa yang sama beliau juga telah diberi pilihan sama ada meletak jawatan atau digugurkan dari parti UMNO. Menurut Dato' Seri Anwar, "I have been asked to resign or chose to be expelled." 17

Dalam bulan yang sama, Dato' Seri Anwar Ibrahim telah dikaitkan dengan isu salahlaku seksual sepertimana yang dinyatakan dalam buku 50 Reasons Why Anwar Shouldn't Be Prime Minister oleh Datuk Khalid Jefri. Datuk Khalid kemudiannya dibicarakan di Mahkamah dengan tuduhan memfitnah. Beberapa penganalisis politik berpendapat, buku tersebut merupakan sebahagian daripada usaha untuk memalukan Dato' Seri Anwar Ibrahim sebagai Timbalan Perdana Menteri dan memaksa beliau untuk meletak jawatan. Beberapa hari kemudian, seorang lelaki tampil dan mendakwa telah diliwat oleh Dato' Seri Anwar sebanyak 15 kali. Pada masa yang sama, seorang peniaga turut membuat laporan bahawa Dato' Seri Anwar pernah menggoda isteri peniaga tersebut. ${ }^{18}$ 
Pihak berkuasa Malaysia telah menjatuhkan hukuman penjara 6 bulan kepada dua orang lelaki yang didapati bersalah kerana membenarkan diri mereka diliwat oleh Dato' Seri Anwar Ibrahim. Mereka merupakan abang angkat dan penasihat Dato' Seri Anwar. Abang angkat Dato' Seri Anwar, Sukma Dermawan mengaku melakukan hubungan homoseksual bersama Dato' Seri Anwar di kediaman rasmi Timbalan Perdana Menteri dalam bulan April 1998. Manakala rakan selaku penasihat Dato' Seri Anwar, Munawar Anees mengaku bersalah membenarkan Dato' Seri Anwar meliwat beliau di rumah persendirian Anwar pada bulan Mac 1993. ${ }^{19}$ Walau bagaimanapun, Dato' Seri Anwar memberi respon ke atas tindakan tersebut sebagai tuduhan daripada Datuk Seri Dr Mahathir dan menyatakan perbuatan itu merupakan kempen untuk memburuk-burukkan beliau. ${ }^{20}$

Disebabkan tindakan Dato' Seri Anwar menentang Perdana Menteri, beliau telah dicadangkan ditahan di bawah Akta Keselamatan Dalam Negeri (ISA). Cadangan ini dikuatkan lagi dengan dakwaan bahawa beliau mempunyai hubungan dengan kumpulan luar Malaysia yang bersifat subversif yang boleh mengancam keselamatan negara. Namun, tuduhan tersebut ditentang oleh Dato' Seri Anwar kerana tidak mempunyai sebarang bukti. ${ }^{21}$ Dalam laporan berita terbitan Utusan Malaysia bertarikh 23 September 1998, bertajuk "PM Jelas Kenapa Anwar Ditahan," Dato' Seri Anwar Ibrahim terpaksa ditahan di bawah Akta Keselamatan Dalam Negeri kerana berucap pada perhimpunan haram yang melibatkan para penyokongnya sehingga membawa kepada perarakan dan rusuhan. Pada awalnya pihak polis merancang untuk mendakwa beliau di mahkamah. ${ }^{22}$

Pada masa yang sama, Dato' Seri Anwar Ibrahim telah berikrar bahawa beliau akan berusaha untuk terus berjuang membersihkan namanya dan menjelaskan sebab UMNO memerlukan pembaharuan politik. Menurut Dato' Seri Anwar, pembaharuan politik perlu dilakukan kerana rakyat Malaysia merasa kurang senang dengan isu rasuah dan kronisme di Malaysia. Dato' Seri Anwar mendakwa usaha beliau itu merupakan amaran dan ancaman kepada Datuk Seri Dr Mahathir. Walau bagaimanapun, tindakan tersebut akhirnya menjadi antara punca beliau disingkirkan. ${ }^{23}$

Selepas Dato' Seri Anwar Ibrahim dipecat, beliau masih meneruskan kempen pembaharuan politik dengan mengadakan perhimpunan di luar Kuala Lumpur. Usaha itu juga bertujuan untuk membersihkan nama beliau yang dituduh menjalinkan hubungan homoseksual. Dato' Seri Anwar turut mendakwa bahawa beliau merupakan mangsa konspirasi politik oleh pihak atasan. ${ }^{24}$ Perhimpunan tersebut dihadiri lebih kurang 6,000 orang penyokong Dato' Seri Anwar. Perhimpunan jalanan juga dibuat pada hujung minggu untuk menyuarakan bahawa beliau tidak bersalah kepada orang awam. ${ }^{25}$

Semasa perhimpunan yang diadakan di Kota Bahru, Dato' Seri Anwar Ibrahim tidak mendapat sebarang tentangan daripada Datuk Seri Dr Mahathir kerana perhimpunan tersebut dijalankan dalam keadaan aman. Walau bagaimanapun, Datuk Seri Dr Mahathir memberi amaran akan bertindak sekiranya perhimpunan itu mengganggu ketenteraman awam. ${ }^{26}$ Menurut laporan akhbar, perhimpunan itu dihadiri lebih kurang 50,000 penyokong Dato' Seri Anwar. Kempen itu juga bertujuan menggesa agar Perdana Menteri meletakkan jawatan. Walau bagaimanapun, Datuk Seri Dr Mahathir menyatakan tindakan Dato' Seri Anwar menggesa beliau meletak jawatan merupakan tindakan yang menyalahi undang-undang negara. Pada masa yang sama, Datuk Seri Dr Mahathir turut memberi amaran kepada penyokong Dato' Seri Anwar dan juga ahli UMNO bahawa sokongan mereka kepada Anwar akan memberi kesan ke atas penilaian kesetiaan mereka kepada parti UMNO. ${ }^{27}$ 
Disebabkan Dato' Seri Anwar enggan mengaku mengenai tuduhan yang dikenakan ke atas beliau, pada 13 September 1998, Ahli Majlis Tertinggi UMNO, Senator Datuk Ibrahim Ali telah mencabar Dato' Seri Anwar Ibrahim untuk bersumpah menjunjung al-Quran bagi membuktikan semua tuduhan terhadapnya adalah tidak benar. Menurut Datuk Ibrahim, beliau terpaksa mencabar Dato' Seri Anwar setelah melihat banyak pihak yang meragui Anwar dilucutkan jawatan dalam kabinet dan dipecat dari UMNO kerana mempunyai masalah moral. Cabaran itu juga dibuat kerana Datuk Seri Dr Mahathir mempunyai cukup bukti mengenai masalah moral Dato' Seri Anwar sehingga terpaksa membuat keputusan memecatnya. ${ }^{28}$

Mengenai gerakan reformasi yang dilancarkan oleh Dato' Seri Anwar Ibrahim, Datuk Ibrahim berpendapat gerakan tersebut diadakan bertujuan untuk menjatuhkan Perdana Menteri dengan cara yang salah demi membersihkan nama Dato' Seri Anwar daripada segala tuduhan. Penahanan ke atas Dato' Seri Anwar Ibrahim telah membawa kepada 21 pendakwaan menentang beliau termasuklah rasuah, sogokan, salahguna kuasa, pengkhianatan dan salah laku seksual. ${ }^{29}$ Disebabkan oleh masalah yang timbul, Datuk Seri Dr Mahathir menyatakan bahawa Dato' Seri Anwar secara moralnya tidak sesuai mentadbir negara Malaysia. ${ }^{30}$

Penahanan Dato' Seri Anwar Ibrahim turut digemparkan dengan kenyataan isteri beliau, Wan Azizah apabila merasa risau sekiranya pihak polis bertindak menyuntik virus HIV kepada Dato' Seri Anwar sebagai usaha untuk membuktikan dakwaan salah laku seksual. Walau bagaimanapun, Datuk Seri Dr Mahathir membalas kenyataan tersebut "We never did this before, so why would we do it now?" Pada masa yang sama Datuk Seri Dr Mahathir juga mendakwa Dato' Seri Anwar Ibrahim telah mencetuskan rusuhan yang boleh mengancam kestabilan dan keselamatan negara. ${ }^{31}$ Pada 29 September 1998, Dato' Seri Anwar telah hadir ke mahkamah dan menyatakan bahawa beliau tidak bersalah ke atas kedua-dua tuduhan berkaitan dengan rasuah dan meliwat. Walau bagaimanapun, kehadiran Dato' Seri Anwar ke mahkamah telah mengejutkan ramai pihak kerana didapati mata beliau lebam. Menurut Datuk Seri Dr Mahathir dan Ketua Polis Negara, Rahim Noor, lebam di mata Dato' Seri Anwar merupakan perbuatan beliau sendiri. ${ }^{32}$

Pada 5 Oktober 1998, Dato' Seri Anwar Ibrahim sekali lagi hadir ke mahkamah dan menyatakan tidak bersalah ke atas tuduhan yang dikenakan ke atas beliau dengan memakai pendakap leher. Dato' Seri Anwar mendakwa beliau telah dipukul semasa berada di bawah tahanan polis. Selepas siasatan dijalankan oleh Suruhanjaya Diraja, didapati lebam di mata Dato' Seri Anwar Ibrahim disebabkan oleh serangan fizikal oleh Ketua Polis Negara, Rahim Noor. Disebabkan tindakan tersebut, Rahim telah memohon maaf dan dijatuhkan hukuman penjara dua bulan dan didenda sebanyak RM2,000. ${ }^{33}$

Penahanan dan pendakwaan ke atas Dato' Seri Anwar Ibrahim turut mendapat kritikan negara jiran Malaysia seperti Filipina, Indonesia dan Thailand. Disebabkan isu tersebut, Presiden Indonesia, B J Habibie mengambil keputusan untuk tidak hadir ke Mesyuarat Kemuncak Serantau ASEAN yang diadakan di Kuala Lumpur. Menurut doktrin ASEAN, negara ahli tidak boleh campur tangan dalam konflik dalaman negara ahli ASEAN yang lain. Walau bagaimanapun, dalam kes penahanan dan pendakwaan Dato' Seri Anwar Ibrahim, peristiwa tersebut telah menaikkan kebimbangan dan kemarahan beberapa pemimpin negara ahli ASEAN. ${ }^{34}$ Presiden Filipina, Joseph Estrada turut menyuarakan kesedihan beliau disebabkan oleh peristiwa tersebut. Hal ini kerana Dato' Seri Anwar Ibrahim merupakan antara rakan karib beliau. Kedua-dua Presiden Filipina dan Indonesia berpendapat, tindakan menahan Dato' Seri Anwar Ibrahim merupakan satu kesilapan kerana tuduhan ke atas 
beliau masih tidak dapat dibuktikan. ${ }^{35}$ Kritikan daripada pemimpin negara jiran Malaysia telah dijawab oleh Datuk Seri Dr Mahathir dan berharap agar para pemimpin ASEAN yang mempertikaikan sistem kehakiman di Malaysia sepatutnya menyerahkan kes Dato' Seri Anwar kepada Mahkamah Malaysia untuk membuat keputusan. Menurut Datuk Seri Dr Mahathir:

Itu hak mereka. Mereka boleh bangkitkan tetapi kita juga boleh bangkitkan tentang keadaan (yang berlaku) di negara mereka. Mereka (negara asing) cuba ajar kita tentang keadilan sedangkan di sini kita tak kira bulu, kerajaan ke bukan kerajaan ke, kulit hijau ke, kuning, biru ke, kita tak kira. ${ }^{36}$

Semasa sesi pendakwaan, Dato' Seri Anwar telah menyatakan tidak bersalah dan mendakwa beliau merupakan mangsa konspirasi politik selepas gagal membuat rayuan beberapa kali. ${ }^{37}$ Perbicaraan hari pertama di Mahkamah berakhir dengan kontroversi apabila hakim makhamah, Augustine Paul tidak membenarkan pemantau asing menghadiri perbicaraan tersebut. Menurut beliau:

Allowing official observers would be an "insult to the court" and give the impression "it may not be dispensing justice. The presence of these people would amount to interference in the powers and functions conferred on me by the constitution. ${ }^{38}$

Pada 14 April 1999, Dato' Seri Anwar telah dijatuhkan hukuman penjara enam tahun atas kesalahan rasuah dan pada 8 Ogos 2000 pula, beliau telah dijatuhkan hukuman penjara selama sembilan tahun atas kesalahan salahlaku seksual. ${ }^{39}$ Namun begitu, pada 12 Mei 2001, lima tuduhan jenayah ke atas Dato' Seri Anwar telah digugurkan oleh pihak pendakwa raya kerana kekurangan bukti. Tuduhan tersebut termasuklah empat dakwaan meliwat di bawah Seksyen 377B Kanun Keseksaan dan satu kes rasuah dan salah guna kuasa mengikut Seksyen 2(1) Ordinan No. 22 (KuasaKuasa Perlu) Darurat $1970 .{ }^{40}$ Pada 2 September 2004, Mahkamah Tinggi Persekutuan membuat keputusan membebaskan Dato' Seri Anwar Ibrahim daripada dakwaan salahlaku seksual iaitu meliwat kerana kekurangan bukti. ${ }^{41}$

\section{Respon Malaysia-AS dalam Kes Penahanan dan Pendakwaan Anwar Ibrahim}

Di Kongres AS, ahli Kongres iaitu Craig Thomas dari Wyoming dan Chris Smith dari New Jersey telah mencadangkan resolusi sebagai respon ke atas kes Dato' Seri Anwar Ibrahim di Malaysia iaitu mengutuk dan mendesak Malaysia agar menggugurkan atau menjalankan perbicaraan semula. Resolusi yang dicadangkan oleh Thomas dan Smith telah mendapat persetujuan Kongres AS. ${ }^{42}$ Perkara ini telah menyebabkan rasa kurang senang di pihak Malaysia. AS dikatakan campur tangan dalam urusan perundangan Malaysia walaupun pada awalnya, AS pernah menyatakan kes tersebut merupakan masalah dalaman Malaysia. Perkara ini jelas dalam terbitan surat khabar Utusan Malaysia bertajuk "Washington anggap pelucutan Anwar politik dalaman." protes layanan pihak berkuasa Malaysia kepada Dato' Seri Anwar Ibrahim apabila muncul di makhamah dengan mata lebam, Presiden AS, Bill Clinton menyatakan tidak akan menemui Datuk Seri Dr Mahathir semasa Persidangan Kemuncak 
Kerjasama Ekonomi Asia Pasifik (APEC) untuk membincangkan mengenai hubungan Malaysia-AS. ${ }^{44}$

Pada masa yang sama, Datuk Seri Rafidah Aziz telah memberi amaran kepada pemimpin negara yang menghadiri APEC agar tidak menimbulkan isu mengenai penahanan dan pendakwaan Dato' Seri Anwar Ibrahim, namun Naib Presiden AS, Al Gore telah bertindak sebaliknya. Perkara ini jelas apabila Utusan Malaysia menerbitkan artikel bertajuk "Al Gore Pemimpin biadab - menghina Malaysia dengan ucapan menyokong perusuh reformasi." 45 Pada 17 November 1998, Al Gore telah menyuarakan sokongannya secara terbuka kepada gerakan reformasi Dato' Seri Anwar Ibrahim yang mencetuskan perhimpunan haram dan rusuhan di Kuala Lumpur. ${ }^{46}$

Tindakan Al Gore telah menyebabkan beliau dikritik sebagai pemimpin Barat yang angkuh, biadab dan lidah bercabang kerana mempromosikan demokrasi tetapi pada masa yang sama telah memuji tindakan para penyokong Dato' Seri Anwar Ibrahim yang dikatakan sebagai liar apabila bertindak ganas memukul anggota polis, membakar kenderaan dan membelasah wartawan. ${ }^{47} \mathrm{Al}$ Gore juga menyatakan bahawa perusuh-perusuh gerakan reformasi sebagai "orang berani Malaysia." Menurut Al Gore:

Ketika beberapa negara anggota mengalami krisis ekonomi, kita terus mendengar tuntutan terhadap demokrasi yang inginkan perubahan dalam pelbagai bahasa - people power dan reformasi. Kita dengar mengenai mereka hari ini, di sini dan sekarang, di kalangan orang Malaysia yang berani. ${ }^{48}$

Kenyataan yang dikeluarkan oleh Al Gore merupakan sokongan terhadap resolusi yang dipersetujui oleh ahli Kongres AS iaitu mengutuk layanan pihak berkuasa Malaysia terhadap Dato' Seri Anwar Ibrahim semasa dalam tahanan. Tindakan Al Gore itu juga telah mendapat reaksi negatif daripada beberapa pemimpin Malaysia sama ada di pihak kerajaan dan juga pembangkang. Contohnya, Timbalan Pengerusi Kelab Penyokong Kerajaan, Datuk Dr Jamaluddin Jarjis melabelkan Al Gore sebagai 'kurang sopan, biadab dan kurang ajar.' Pemangku Ketua Pergerakan Pemuda UMNO, Datuk Hishammuddin Tun Hussein pula telah bertindak menghantar memorandum bantahan ke Kedutaan AS berhubung kenyataan Al Gore. ${ }^{49}$

Menurut Presiden MCA, Datuk Yap Pian Hon, "Sepatutnya ucapan beliau (A1 Gore) menyentuh soal ekonomi dan bukan berkhutbah kepada orang lain mengenai demokrasi tanpa mengetahui kedudukan sebenar politik negara ini." Ketua Pergerakan Pemuda MCA, Datuk Chan Kong Choy pula dalam nada marah menyatakan perbuatan AS itu "adalah kasar dan telah melukakan perasaan rakyat Malaysia." 50

Pemimpin-pemimpin pro-kerajaan tidak bersendirian dalam mengecam AS kerana beberapa pemimpin parti pembangkang turut melahirkan perasaan tidak senang. Menurut ahli Parlimen PAS, Mohamad Sabu, "Bagi saya komen AS merugikan penyokong Anwar Ibrahim sebab selalunya apabila AS berada di belakang sesuatu perkara, mereka tidak menjadi popular kepada orang ramai." Presiden Parti Rakyat Malaysia (PRM), Dr Syed Husin Ali pula berpendapat Al Gore tidak mempunyai hak moral untuk berkhutbah mengenai demokrasi dan hak asasi manusia selepas AS menyebabkan begitu banyak kematian serta kesengsaraan terutama dalam kalangan kanak-kanak termasuk di Cuba dan Iraq. ${ }^{51}$ 
Timbalan Pengerusi DAP, Karpal Singh juga telah menyertai senarai panjang mereka yang mengutuk tindak tanduk Al Gore. Karpal Singh yang mewakili Dato' Seri Anwar Ibrahim dalam satu kes mahkamah mengecam pemimpin AS berkenaan sebagai "tidak berbudi bahasa." Dalam kalangan ahli perniagaan, mereka melihat kenyataan Al Gore dengan sentimen negatif mengenai bahaya sikap AS terhadap perdagangan dunia. Presiden Dewan Perniagaan Melayu Malaysia (DPMM), Tan Sri Tajudin Ramli menyifatkan ucapan Al Gore sebagai mencabar maruah bangsa Malaysia. Selain Malaysia, tindakan Al Gore juga telah dikritik oleh pemimpin negara lain seperti Perdana Menteri Singapura, Goh Chok Tong yang menyifatkan Al Gore tidak wajar bersikap sedemikian kerana ia terkeluar daripada landasan APEC sebagai forum ekonomi. ${ }^{52}$

Tindakan Al Gore turut menaikkan kemarahan rakyat Malaysia. Menurut Utusan Malaysia, ibu pejabat Utusan telah menerima banyak panggilan telefon dan kenyataan melalui faks daripada orang ramai yang marah dengan campur tangan AS dan ada yang menyifatkan tindakan AS sebagai kolonialisme baharu. Disebabkan tindakan Al Gore dilihat mampu menambah ketegangan dalam hubungan MalaysiaAS, seorang ahli perniagaan AS, Richard Holwill yang juga merupakan bekas duta AS ke Ecuador dan pengerusi Bersama Pasukan Petugas Khas Dewan Perniagaan AS telah memohon maaf ke atas kenyataan Al Gore. Menurut Holwill, "Gore menunjukan satu kejahilan yang tidak boleh dimaafkan terhadap keadaan sebenar di sini (Malaysia)." ${ }^{, 53}$ Walau bagaimanapun, surat khabar AS terutamanya New York Times menyokong perbuatan $\mathrm{Al}$ Gore dan menyifatkan tindakan tersebut sebagai wajar dilakukan ke atas Malaysia dalam artikel bertajuk "Championing Democracy in Malaysia."

Diplomatic protocol calls for speaking positively of one's hosts. Mr. Gore, Ms. Albright and the others were right to be rude. America's interest in Asia is to encourage human rights and democratic change, not to flatter embattled autocrats. ${ }^{54}$

Menurut Tun Dr Mahathir, tindakan surat khabar New York Times menyokong tindakan Al Gore merupakan manifestasi media Barat yang tidak cenderung dan kurang mesra dengan kerajaan Malaysia. Oleh itu, isu penahanan dan pendakwaan Dato' Seri Anwar Ibrahim dijadikan peluang kepada media Barat yang menentang Malaysia sebagai saluran untuk mempromosikan masalah mereka terhadap Malaysia. Hubungan yang kurang mesra ini juga menjadi peluang kepada parti lawan untuk menentang kerajaan Malaysia yang dipimpin oleh parti UMNO. Walau bagaimanapun, menurut Dato Ilango, sikap kurang mesra pihak surat khabar arus perdana AS mempunyai kaitan dengan sikap Datuk Seri Dr Mahathir yang lantang mengkritik negara-negara Barat khususnya AS. ${ }^{55}$ Tindakan Datuk Seri Dr Mahathir mengkritik AS diakui sendiri oleh beliau menerusi kutipan di bawah:

Dasar kita berkecuali, kita tidak support AS secara terbuka atau buta tuli, tetapi kita kalau ada kesalahan yang dilakukan oleh AS, kita buat teguran di Parlimen, di UN. Jadi ini tidak menyenangkan kuasa besar ini. Jadi bila tidak menyenangkan kuasa besar, terutamanya di akhbarakhbar mereka, mereka memang akan memburuk-burukkan keadaan di Malaysia. Sedangkan Malaysia adalah sebuah negara membangun yang lebih maju dari negara-negara lain, yang stabil dari segi politik yang boleh mengadakan pilihanraya tiap 5 tahun. Semua itu 
diketepikan. Development di Malaysia jarang dilapor. Cuma yang buruk sahaja dilapor. Ini memang kerja akhbar AS, mereka memang mempunyai persepsi tertentu dan dasar tertentu dan mereka tidak akan puji Malaysia melainkan jika kita terima segala dasar-dasar Barat yang kita kritik. Tapi AS dan akhbar mereka memang tidak beri apa-apa gambaran yang jelas mengenai kejayaan-kejayaan di Malaysia. ${ }^{56}$

Pada 18 Oktober 1998, Datuk Seri Dr Mahathir telah membuat kenyataan bahawa tindakan Al Gore yang memberikan sokongan terbuka kepada gerakan reformasi tidak menjejaskan hubungan Malaysia-AS. Hal ini kerana sepanjang pertemuan Datuk Seri Dr Mahathir dan Al Gore pada setiap sesi sidang kemuncak, mereka tidak pernah membincangkan isu mengenai politik dalaman Malaysia. Menurut beliau tidak wujud ketegangan antara Malaysia dan AS serta menyerahkan perkara tersebut kepada Menteri Luar, Dato' Seri Abdullah Ahmad Badawi. ${ }^{57}$ Walau bagaimanapun, pada 31 Januari 1999, Datuk Seri Dr Mahathir bertindak mengkritik perbuatan Al Gore yang didakwa tidak demokratik kerana menerima demonstrasi sebagai cara untuk menghalang seseorang daripada didakwa di mahkamah setelah melakukan sesuatu yang bertentangan dengan undang-undang. ${ }^{58}$ Menurut Datuk Seri Dr Mahathir:

Mengenai demokrasi, kami mengadakan pilihan raya secara tetap. Kerajaan yang ada adalah kerajaan yang dipilih. Apa yang berlaku sekarang ialah terdapat cubaan untuk menggunakan cara tidak demokratik seperti demonstrasi di jalanan untuk menggulingkan kerajaan yang dipilih. Saya tidak faham bagaimana ahli Demokrat boleh datang ke negara kita dan mendesak rakyat untuk berdemonstrasi di jalanan dan menggulingkan kerajaan yang dipilih. Saya tidak tahulah sama ada itu yang dikatakan demokratik atau pilihan raya yang dijalankan secara betul adalah demokratik. Untuk mengatakan bahawa rakyat Malaysia tidak boleh bercakap dan menyuarakan pendapat mereka adalah karut semata-mata. ${ }^{59}$

Semasa persidangan Parlimen pada 14 Disember 1998, ahli parlimen Yim Chee Yong dari Negeri Sembilan mengkritik perbuatan Al Gore sebagai bersikap biadap kerana mengganggu hal ehwal dalaman negara Malaysia. Yim Chee Yong telah mendesak Kementerian Dalam Negeri terutama Cawangan Khas untuk menyiasat sama ada AS menggunakan wang untuk menggulingkan kerajaan. Sekiranya AS didapati berbuat sedemikian, beliau berharap kerajaan Malaysia mengambil tindakan sewajarnya untuk menentang niat jahat AS tersebut. ${ }^{60}$

Selepas Dato' Seri Anwar dijatuhkan hukuman penjara selama sembilan tahun, AS telah mempertikai dan mengkritik cara kerajaan Malaysia mengendalikan kes Dato' Seri Anwar Ibrahim. Kritikan tersebut telah menaikkan kemarahan Malaysia. Perkara ini jelas apabila Malaysia memberi amaran kepada AS dan Australia kerana mempertikaikan kewibawaan sistem kehakiman dan perundangan Malaysia mengenai keputusan kes liwat Dato' Seri Anwar Ibrahim. Hukuman penjara sembilan tahun yang diputuskan oleh Mahkamah Tinggi Kuala Lumpur dibuat mengikut sistem undang-undang dan perlembagaan Malaysia. ${ }^{61}$

Kenyataan bantahan ke atas keputusan Mahkamah telah dibuat oleh jurucakap Jabatan Negara AS, Richard Boucher dan Perdana Menteri Australia, John Howard. Howard melalui rangkaian Radio ABC di Sydney telah mempertikaikan kebebasan 
kehakiman Malaysia dan beranggapan hukuman tersebut sebagai kempen politik yang tidak berpenghujung. Manakala Boucher yang mewakili AS menyatakan kerajaan AS sedih dan marah dengan hukuman yang dijatuhkan berturut-turut ke atas Dato' Seri Anwar Ibrahim selepas selesai menjalani hukuman penjara enam tahun kerana kesalahan rasuah. AS juga telah menuduh polis Malaysia melatih saksi utama pendakwaan, menghasut seorang peguam Dato' Seri Anwar serta keengganan mahkamah membenarkan Dato' Seri Anwar memanggil saksi penting yang dianggap boleh menyokong hujahnya bahawa Dato' Seri Anwar merupakan mangsa konspirasi politik. ${ }^{62}$ Menurut Menteri Pertahanan Malaysia, Datuk Seri Najib Razak:

Kami yakin apa-apa keputusan yang dibuat berdasarkan sistem keadilan yang telah melalui proses membentangkan hujah-hujah yang diteliti oleh hakim. Dan hakim telah membuat keputusan berdasarkan pengamatan-pengamatan sesuatu yang boleh disabitkan kesalahan (ke atas Anwar). Jadi, jangan ada campur tangan dari luar. Jangan campur tangan dalam urusan dalaman Malaysia. ${ }^{63}$

Sementara itu, Naib Presiden UMNO, Tan Sri Muhammad Muhd. Taib menyatakan kekecewaan beliau dengan kenyataan pemimpin AS dan Australia yang mengkritik sistem kehakiman Malaysia. Menurut beliau, AS dan Australia sepatutnya menghormati sistem perundangan Malaysia. ${ }^{64}$ Selain itu, kerajaan Malaysia juga telah mengarahkan Dato Ilango mewakili duta besar Malaysia di AS ke Jabatan Negara AS untuk memberi penjelasan mengenai perjalanan perbicaraan kes Dato' Seri Anwar Ibrahim. Bagi Dato Ilango, ketegangan juga berlaku apabila terdapat ahli politik Malaysia menyuarakan mengenai sesuatu perkara yang dikatakan tidak masuk akal dan kemudiannya dilaporkan oleh surat khabar.

Saya pada masa itu instructed to come to state department to explain. Ahli politik kita pada masa itu lantang bercakap, mereka fikir apa-apa yang mereka katakan hanya difaham dan ditangkap oleh media lokal sahaja. Saya rasa mereka lupa terus, apa yang mereka cakap itu boleh sampai keluar negara. Kalaupun media Barat tidak menangkap semuanya, bukan bermaksud mereka langsung tak mengikuti. Ia dibaca tapi dia tak bagi apa-apa komen, bila ahli politik kita kata sesuatu yang tidak masuk akal. ${ }^{65}$

Pada awal tahun 2000, Setiausaha Negara AS, Madeleine Albright telah menyerahkan laporan tahunan kajian amalan hak asasi manusia yang disediakan oleh Jabatan Negara AS. Laporan kajian itu kemudiannya diserahkan kepada Kongres AS. Menurut laporan tersebut, Dato' Seri Anwar Ibrahim telah dituduh meliwat dan menyalahgunakan kuasa yang membuktikan wujudnya pencabulan hak asasi manusia di Malaysia. ${ }^{66}$ Berdasarkan laporan itu juga, dua orang pakar akademik iaitu Peter Van Dijk dari Belanda dan Torsten Wiesel dari AS telah membuat laporan yang mendakwa berlaku pelanggaran hak asasi manusia oleh Malaysia terhadap Dato' Seri Anwar Ibrahim ke Committee of Convension and Recommendations (CCRE) UNESCO. ${ }^{67}$

Kes berkenaan telah dibincangkan sebanyak lapan kali bermula tahun 2000 hingga 2004. Malaysia melalui Kementerian Pelajaran, Kementerian Luar Negeri, Kementerian Kesihatan, Jabatan Peguam Negara dan Jabatan Penjara Malaysia telah menghadiri mesyuarat $\mathrm{CCRE}$ dan mengambil pelbagai tindakan untuk menangkis 
dakwaan tersebut. Antara tindakan yang telah dibuat termasuklah menyediakan jawapan terperinci secara bertulis dan memberi maklumat tambahan mengenai pendakwaan mahkamah serta menghantar satu salinan Seksyen 37 (1) Akta Penjara 1995 kepada CCRE. Usaha kerajaan Malaysia untuk meyakinkan UNESCO bahawa badan kehakiman Malaysia adalah telus, adil dan bebas berhasil apabila UNESCO membuat keputusan menolak dakwaan bahawa Malaysia telah melanggar hak asasi manusia semasa membicarakan kes Dato' Seri Anwar Ibrahim. Keputusan tersebut telah dicapai dalam mesyuarat CCRE pada 29 dan 30 September 2004 bertempat di ibu pejabat UNESCO di Paris, Perancis. ${ }^{68}$

Selain berhadapan dengan CCRE, pada 27 Oktober 2000, beberapa orang ahli Kongres telah mencadangkan satu resolusi untuk menggesa kerajaan Malaysia agar menggugurkan kesemua tuduhan ke atas Dato' Seri Anwar Ibrahim atau mengadakan perbicaraan baharu. ${ }^{69}$ Tindakan ini telah menaikkan kemarahan pemimpin Malaysia. Tindakan mencadangkan resolusi itu juga dilakukan selepas penyokong Dato' Seri Anwar Ibrahim mengupah sebuah firma perunding antarabangsa di Washington untuk melobi ahli Kongres dalam perancangan memburuk-burukkan kerajaan Malaysia serta mengenakan tekanan ekonomi dan politik untuk membebaskan Dato' Seri Anwar Ibrahim. $^{70}$

Sejak bulan Ogos 2000, penyokong Dato' Seri Anwar Ibrahim telah mengikat kontrak selama empat bulan dengan firma hal ehwal perhubungan awam dan strategi politik iaitu Janus Meritt Strategy (JMS). Kontrak tersebut membabitkan bayaran sebanyak AS\$50,000 (RM190,000). Melalui kontrak itu, JMS telah merangka dan mengusahakan program untuk mengenakan tekanan politik dan ekonomi kepada Malaysia termasuklah memperkenalkan undang-undang sekatan dalam Kongres AS, menyekat bantuan ketenteraan dan memboikot barangan buatan Malaysia. ${ }^{71}$

Menurut laporan Utusan Malaysia dan kenyataan daripada Ketua Pemuda Parti Keadilan Nasional (Keadilan), Ezam Mohd. Noor, JMS telah mengadakan perjumpaan makan tengahari dengan 11 kakitangan beragama Islam yang berkhidmat dengan anggota Kongres AS di sebuah restoran di Washington. Selain itu, JMS juga telah mengadakan pertemuan dengan pasukan kempen bagi jawatan Presiden, George W Bush untuk memberi jaminan sokongan masyarakat Islam AS kepada Bush jika beliau mengeluarkan kenyataan mengutuk Malaysia berhubung kes Dato' Seri Anwar Ibrahim. $^{72}$

Selain itu, JMS juga menggunakan khidmat penyelidik firmanya iaitu Omar Nashashibi yang berasal dari Palestin untuk mengajurkan demonstrasi di hadapan kedutaan Malaysia di Washington semasa lawatan Datuk Seri Dr Mahathir ke Chicago pada 3 September 2000. Melalui perhubungan awam JMS dan Institut Antarbangsa Pemikiran Islam (IIIT), pengarah IIIT, Dr Jamal Barazinghi juga aktif mengadakan kempen bagi membebaskan Dato' Seri Anwar. Hal ini kerana IIIT mempunyai hubungan rapat dengan Dato' Seri Anwar Ibrahim. Tambahan pula, IIIT juga mempunyai hubungan rapat dengan ahli Kongres AS (Dewan Perwakilan) yang mewakili parti Demokrat kawasan Michigan iaitu David E. Bonnior yang mempunyai pengaruh di Dewan Perwakilan AS. ${ }^{73}$

Walau bagaimanapun, resolusi yang dicadangkan oleh ahli Kongres selepas dilobi oleh JMS hanya menggesa Malaysia agar menggugurkan kesemua tuduhan ke atas Dato' Seri Anwar atau mengadakan perbicaraan baharu. Pada 7 November 2000, Kelab Senator Malaysia (KSM) telah meminta jasa baik Duta AS di Malaysia, B. Lynn Pascoe untuk menjelaskan kepada semua ahli Kongres AS mengenai proses perundangan Malaysia. Menurut Presiden KSM, Senator Datuk Aziz Abdul Rahman: 
Adalah amat dikesali bahawa sebagai penggubal undang-undang, mereka telah menuntut kerajaan yang dipilih oleh rakyat negara ini menggugurkan semua tuduhan atau mengadakan perbicaraan baru sedangkan proses pengadilan dijalankan secara terbuka. Ketidakfahaman ini harus diperjelaskan. Kami meminta jasa baik pihak Kedutaan AS di Malaysia untuk memberikan penjelasan mengenai gambaran sebenar. ${ }^{74}$

KSM juga memberi peringatan kepada ahli Kongres AS yang terlibat supaya jangan memandang ringan protes rakyat Malaysia ke atas tindakan mereka:

Bantahan ini tidak boleh dipandang kecil kerana ia datang dari semua lapisan rakyat daripada kaum pekerja, CUEPACS, MTUC, belia, kalangan profesional dan pertubuhan politik serta para pegawai perundangan seperti bekas Hakim Mahkamah Agung, Tan Sri Harun Hashim. ${ }^{75}$

Kerajaan Malaysia melalui Kementerian Luar Negeri juga telah bertindak mengeluarkan kenyataan keras mengutuk tindakan ahli Kongres AS yang terlibat. Di samping itu, Duta Besar Malaysia di AS telah bertemu dengan beberapa ahli Kongres untuk menyampaikan rasa tidak puas hati kerajaan Malaysia dan menjelaskan perkara yang sebenarnya. Menurut Timbalan Menteri Luar Negeri, Datuk Dr Leo Micheal Toyad, ahli Kongres AS berpuas hati dengan penjelasan tersebut dan tindakan mereka tidak memberi kesan kepada kerajaan Malaysia. Tambahan pula, ketujuh-tujuh ahli Kongres terlibat sengaja tidak mahu memahami sistem pentadbiran kerajaan Malaysia di mana terdapat pemisah antara badan eksekutif dan badan perundangan. Beliau juga percaya bahawa ahli Kongres AS yang mencadangkan resolusi menggugurkan kesemua tuduhan ke atas Dato' Seri Anwar Ibrahim hanyalah alat oleh penyokong Dato' Seri Anwar yang cuba memburuk-burukkan kerajaan Malaysia. ${ }^{76}$

\section{Langkah-langkah Diambil Kerajaan Malaysia dan AS bagi Mengurangkan Ketegangan}

Peristiwa penahanan dan pendakwaan Dato' Seri Anwar Ibrahim telah meningkatkan ketegangan dalam hubungan Malaysia-AS. Walau bagaimanapun, kedua-dua buah negara tidak membiarkan isu tersebut berlanjutan. Menurut Dato Ilango, kritikan yang dibuat oleh Malaysia bukan bertujuan untuk memusuhi AS kerana kerajaan Malaysia masih lagi menghantar beberapa pegawai khususnya duta Malaysia bagi menjelaskan dan meyakinkan AS bahawa hubungan kedua-dua buah buah negara tidak terjejas kerana isu tersebut. Tindakan ini juga bertujuan untuk menunjukkan kepada AS bahawa Malaysia masih lagi rakan baik dalam bidang-bidang lain. Malaysia hanya tidak bersetuju dengan kritikan dan campur tangan AS dalam pentadbiran dan perundangan Malaysia khususnya berkaitan kes penahanan dan pendakwaan Dato' Seri Anwar Ibrahim. ${ }^{77}$

Bagi mengurangkan ketegangan dalam hubungan Malaysia-AS, diplomat AS di Kuala Lumpur telah dihantar ke Wisma Putra untuk berbincang dengan kerajaan Malaysia. Semasa berada di Wisma Putra, diplomat AS telah memohon agar pihak pentadbiran Malaysia mengurangkan kritikan ke atas AS kerana perbuatan tersebut dipandang tidak baik bagi hubungan kedua-dua buah negara. Perkara tersebut 
kemudiannya dilaporkan kepada Kabinet khususnya kepada Perdana Menteri, Datuk Seri Dr Mahathir. Selepas mendapat laporan tersebut, ia terpulang kepada Datuk Seri Dr Mahathir untuk mengambil tindakan yang sesuai bagi mengendalikan isu tersebut. Oleh itu, Datuk Seri Dr Mahathir telah mengurangkan kritikannya ke atas AS. ${ }^{78}$

Di sebalik masalah yang wujud antara Malaysia dan AS, pada tahun 2001 selepas peristiwa 11 September 2001 iaitu serangan pengganas ke atas Pusat Dagangan Dunia AS di New York, Malaysia dan AS telah meningkatkan kerjasama iaitu memerangi keganasan global. Walau bagaimanapun, AS masih tidak mengubah pendirian mengenai status Dato' Seri Anwar Ibrahim sebagai tahanan politik. Menurut Menteri Luar Malaysia, Datuk Seri Syed Hamid Albar, hubungan MalaysiaAS sukar meningkat jika isu berkaitan Dato' Seri Anwar Ibrahim dianggap kunci atau isu terpenting dalam hubungan kedua-dua negara. Perkara tersebut telah dimaklumkan berkali-kali kepada pegawai dan diplomat AS termasuk ahli Kongres AS. $^{79}$

Hal ini kerana Datuk Seri Syed Hamid Albar melihat isu ini akan sentiasa didebatkan dalam hubungan kedua-dua buah negara. AS tetap tidak berpuas hati sekiranya tidak dapat mempengaruhi Malaysia. Oleh itu, untuk meneruskan hubungan baik dengan AS, isu yang dianggap penting oleh AS perlu diselesaikan. Tindakan itu juga diambil kerana Malaysia tidak mahu kes Dato' Seri Anwar Ibrahim menganggu hubungan Malaysia-AS secara keseluruhan. ${ }^{80}$ Hubungan Malaysia-AS kembali pulih apabila Mahkamah Tinggi Persekutuan mengambil keputusan membebaskan Dato' Seri Anwar Ibrahim daripada dakwaan meliwat pada 2 September 2004. Keputusan itu juga telah mengubah pandangan AS ke atas sistem kehakiman Malaysia yang pada mulanya dikatakan tidak bebas. Pamela Sodhy menyimpulkan, keputusan membebaskan Dato' Seri Anwar Ibrahim membawa perubahan besar dalam hubungan Malaysia-AS. ${ }^{81}$ Christopher J. LaFleur, duta AS di Malaysia menyatakan bahawa:

\section{Malaysia's Federal Court had freed former Deputy Prime Minister Anwar Ibrahim by overturning a highly questionable conviction a very encouraging demonstration of the rule of law and the independence of Malaysia's judiciary. ${ }^{82}$}

Persengketaan hubungan di antara Malaysia-AS dalam peristiwa penahanan dan pendakwaan Dato' Seri Anwar Ibrahim mengambil masa hampir enam tahun untuk diselesaikan. Ketegangan ini dileraikan sementara waktu selepas Dato' Seri Anwar dibebaskan. Walaupun peristiwa ini sedikit sebanyak telah menjejaskan hubungan Malaysia-AS dalam tempoh dari tahun 1998 hingga 2004, namun ia tidak menjejaskan keseluruhan hubungan kedua-dua buah negara khususnya dalam asepk ekonomi. Walau bagaimanapun, peristiwa penting ini tetap utuh dalam lipatan sejarah hubungan kedua-dua buah negara.

\section{Kesimpulan}

Peristiwa penahanan dan pendakwaan Dato' Seri Anwar Ibrahim mempunyai impak yang tersendiri dalam hubungan Malaysia-AS. Perkara ini dilihat begitu ketara apabila peristiwa ini mampu menjejaskan keharmonian kedua-dua buah negara. Peristiwa ini turut mempengaruhi ahli Kongres AS termasuklah Presiden dan Timbalan Presiden AS sehingga mencadangkan beberapa resolusi sebagai respon kepada layanan pihak berkuasa Malaysia ke atas Dato' Seri Anwar Ibrahim. AS 
dilihat lebih berpihak kepada Dato' Seri Anwar Ibrahim kerana menganggap Anwar sebagai tahanan dan mangsa konspirasi politik. Kritikan yang menyatakan Malaysia sebagai negara yang tidak demokratik dan melanggar hak asasi manusia juga turut dibincangkan oleh AS di Kongres. Malaysia membalas kritikan dan dakwaan tersebut dengan mengeluarkan kenyataan AS tidak sepatutnya campur tangan dalam sistem pentadbiran Malaysia. Hal ini menunjukkan bahawa walaupun AS sebagai sebuah negara besar dan berkuasa di peringkat antarabangsa, namun Malaysia tidak tunduk dengan desakan AS untuk menggugurkan dakwaan ke atas Dato' Seri Anwar Ibrahim.

Di samping itu, pihak kerajaan dan pembangkang di Malaysia telah bekerjasama mengkritik tindakan AS. Perkara tersebut disebabkan campur tangan AS yang dikatakan mengganggu dan merumitkan lagi perjalanan proses perbicaraan ke atas Dato' Seri Anwar Ibrahim. Justeru, peristiwa penahanan dan pendakwaan Dato' Seri Anwar Ibrahim dilihat sebagai masalah dalaman sedikit sebanyak menjejaskan hubungan Malaysia-AS melalui campur tangan AS. Peristiwa ini juga telah meningkatkan ketegangan dalam hubungan kedua-dua buah negara. Walau bagaimanapun, kedua-dua negara telah mengambil langkah bagi mengurangkan ketegangan khususnya yang berkaitan dengan peristiwa ini. Justeru itu, peristiwa ini memperlihatkan bahawa masalah dalaman sesebuah negara juga mampu mempengaruhi hubungan negara tersebut di peringkat antarabangsa.

\section{Nota}

$1 \quad$ Pamela Sodhy, Malaysia-US Relations 2000-2011, Kuala Lumpur: Institute of Strategic \& International Studies (ISIS), 2011.

Mark Trowell, Sodomy II: The Trail of Anwar Ibrahim, Singapore: Marshall Cavendish, 2012. Mas Juliana Mukhtaruddin, "An Evaluation of Malaysia's Political Leadership in MalaysiaUS Relations in the Post 9/11 Era." Journal of International Studies, 2015; Shakila Yacob, The United States and the Malaysian Economy, London: Routledge, 2008; Aszlan Selamat, "Hubungan Strategik Amerika Syarikat-Malaysia Memerangi Keganasan, 1990-2003”, Tesis Sarjana, Fakulti Kemanusiaan, Seni dan Warisan, Universiti Malaysia Sabah, 2014; Ahmad Hamizan bin Mohd Yusof, United States-Malaysia Relations under Clinton and Bush Administrations, Bangi: UKM, 2008.

4 Mahathir Mohammad, Doktor Umum: Memoir Tun Dr MahathirMohammad, Selangor: MPH Publishing, 2012, h. 814.

New Straits Times, 4 September 1998.

Temu bual Tan Sri Syed Hamid Albar, Bukitsetia Damansara, 27 Januari 2018.

Ibid.

Utusan Malaysia, 4 September 1998.

$B B C, 4$ September 1998.

Mahathir Mohamad, Doktor Umum: Memoir Tun Dr Mahathir Mohammad, h. 822-823.

$B B C$, 4 September 1998.

New York Times, 6 Oktober 1998.

Utusan Malaysia, 6 September 1998.

Ibid.

$B B C, 13$ September 1998.

$B B C, 4$ September 1998.

Ibid.

Ibid.

Utusan Malaysia, 19 September 1998.

New York Times, 21 September 1998.

BBC, 4 September 1998.

Utusan Malaysia, 23 September 1998.

Ibid.

New York Times, 13 September 1998. 
New Straits Times, 14 September 1998.

Ibid.

Ibid.

Utusan Malaysia, 14 September 1998.

Ibid.

New Straits Times, 14 September 1998.

$B B C, 21$ September 1998.

$B B C, 30$ September 1998.

$B B C, 17$ Ogos 2016.

$B B C, 4$ Oktober 1998.

Ibid.

Utusan Malaysia, 16 Oktober 1998.

$B B C, 2$ September 1998.

Ibid.

New York Times, 15 April 1999; New York Times, 9 Ogos 2000. Lihat juga Mark Trowell, Sodomy II: The Trail of Anwar Ibrahim, h. 29.

Utusan Malaysia, 13 Mei 2001.

New Straits Times, 3 September 2004.

Rekod Kongres, Expressing the sense of the senate with respect to Malaysia, $105^{\text {th }}$ Congress, $2^{\text {nd }}$ Session, Vol. 144, No. 151, Washington DC, 21 Oktober 1998, h. 12944-12945.

Utusan Malaysia, 3 September 1998.

$B B C, 11$ November 1998; BBC, 13 November 1998.

Utusan Malaysia, 18 November 1998.

New York Times, 17 November 1998.

Utusan Malaysia, 18 November 1998.

Ibid.

Utusan Malaysia, 13 November 1998.

Utusan Malaysia, 18 November 1998.

Ibid.

Ibid.

Ibid.

New York Times, 18 November 1998.

Semasa isu penahanan dan pendakwaan Dato' Seri Anwar Ibrahim (1998-2004), Dato Ilango menyandang jawatan sebagai Penolong Setiausaha Perancangan Dasar, Kementerian Luar Negeri. Beliau turut dilantik sebagai wakil duta besar Malaysia ke AS bagi menjelaskan kepada kerajaan AS bahawa kes Dato' Seri Anwar Ibrahim dikendalikan dengan adil. Temu bual Dato Ilango Karuppannan, Institut Diplomasi dan Hubungan Luar Negeri, 5 Disember 2017.

Temu bual Tun Dr Mahathir Mohammad, Yayasan Kepimpinan Perdana, 23 November 2017. Utusan Malaysia, 19 November 1998.

Utusan Malaysia, 1 Februari 1999.

Ibid.

Penyata Rasmi Parlimen, Parlimen Kesembilan, Penggal Keempat, Mesyuarat Ketiga, Bil. 30, Cawangan Dokumentasi Parlimen Malaysia, 14 Disember 1998, h. 20.

Utusan Malaysia, 10 Ogos 2000.

Ibid.

Ibid.

Ibid.

Temu bual Dato Ilango Karuppannan.

Utusan Malaysia, 1 Mac 2000.

CCRE UNESCO merupakan jawatankuasa di bawah Lembaga Kerja UNESCO yang diberi mandat untuk membincangkan dan menyelesaikan kes-kes pelanggaran hak asasi manusia di sesebuah negara di bawah bidang pengkhususan UNESCO iaitu pendidikan, sains dan kebudayaan. Utusan Malaysia, 5 Februari 2005.

Ibid.

Laporan berita ini telah tersilap meletakkan tarikh cadangan resolusi oleh ahli Kongres iaitu pada 21 Oktober 2000. Berdasarkan rekod Kongres, tarikh sebenar ialah pada 27 Oktober 2000. Utusan Malaysia, 8 November 2000.

Utusan Malaysia, 27 Oktober 2000. 
Penyata Rasmi Parlimen, Dewan Negara, Bil. 30, Parlimen Kesepuluh, Cawangan Dokumentasi Parlimen Malaysia, 20 Disember 2000, h.13-14.

Utusan Malaysia, 27 Oktober 2000.

Ibid.

Ibid.

Ibid.

Penyata Rasmi Parlimen, Dewan Negara, Parlimen Kesepuluh, Penggal Kedua, Mesyuarat Ketiga, Bil. 28, Cawangan Dokumentasi Parlimen Malaysia, 18 Disember 2000, h.10.

Temu bual Dato Ilango Karuppannan.

Ibid.

Utusan Malaysia, 11 April 2001.

Temu bual Tan Sri Syed Hamid Albar, Bukitsetia Damansara, 27 Januari 2018.

Pamela Sodhy, "Malaysia-US Relations," dalam Abdul Razak Baginda (eds.), Malaysia's Foreign Policy: Continuity \& Change, Malaysia: Marshall Cavendish Sdn. Bhd., 2007, h. 35.

82 Christopher J. La Fleur, Designate to Malaysia submitted to the US Senate Committee on Foreign Relation, Bureau of International Information Programmes, US Department of State, 10 September 2004.http://www.usinfo.state.gov (18 Februari 2018). 